\title{
The Regulation of Food Science and Technology Professions in Europe
}

\author{
Rui Costa ${ }^{\mathrm{a}}$, Sonja Smole MoŽInA ${ }^{\mathrm{b}}$, And PaOla Pittia ${ }^{\mathrm{c}}$ \\ a* CERNAS/ Escola Superior Agrária, Instituto Politécnico de Coimbra, Coimbra, Portugal \\ ${ }^{\mathrm{b}}$ University of Ljubljana, Biotechnical Faculty, Department of Food Science and Technology, Ljubljana, \\ Slovenia \\ ${ }^{\mathrm{c}}$ University of Teramo, Facoltà di Bioscienze e Tecnologie Agro-alimentari ed Ambientali , Mosciano \\ Sant'Angelo (TE) Italy \\ ${ }^{*}$ Corresponding author \\ ruicosta@esac.pt \\ TEL: +351239802940 \\ FAX: +351239802979
}

Received: 10 September 2013; Published online: 18 April 2014

\begin{abstract}
The regulation of a profession is justified when it improves consumer protection and public health. Higher education food science and technology (FST) degrees, widely offered in many universities in Europe open to a wide range of jobs in the food sectors where the employees could cover different positions, roles and carry out diverse activities dealing with the food production and the quality and safety of the food products.

This work reviews the state of the art of the FST regulated professions requiring higher education qualifications in the European countries. The research was carried out by collecting specific information on regulated professions by contacting unions, professional associations, public servant categories/professions, and by visiting national and EU websites. The data collected for each regulated profession were: country, training/education required, date of implementation of regulation, professional training (if required), capability test (if required) and acts required by law to be signed by a regulated professional. Only professions that required a higher education diploma were included in this search.

Few countries were found to have a regulated profession in FST, in particular: Food Engineering (Turkey), Food Technologist (Greece, Iceland, Italy and Slovenia), and Oenologist (Italy, Portugal and Spain). FST regulated professions in Europe are thus scarce and have a rather limited history. The Food Technologist in Italy and the Food Engineer in Turkey were found to be the only completely regulated professions found in Europe. Food and professional regulation have been evolved over the years and raised the debate on the regulation of FST professions. Academia as well as other policymakers has to further contribute to this discussion to keep high the standards for quality of education and training of the qualified workforce and professionals in the food sector.
\end{abstract}

Keywords: Regulation of professions; Food science and technology; Consumer protection; Public health

\section{Introduction}

The production, processing and distribution of food is the largest and most important economic 
activity in the world and in the EU, where the Food and Drink industry is the leading manufacturing sector exceeding $€ 1000$ billion turnover (FDE, 2012). The large workforce in the food sector comprises a variety of professionals having different levels of education and training (e.g. secondary school, $1^{\text {st }}$ or $2^{\text {nd }}$ level degree, $\mathrm{PhD})$ in technical and scientific areas of food science and technology/engineering and/or of foodrelated ones such as agriculture, chemistry, economics, medicine and nutrition, and they may have different occupation and job responsibilities (research, development, quality assurance and control, production) in various public and private food-related entities.

The food technology/engineering scientific area is a rather new discipline that developed in Europe in the early 1950s (Kostaropoulos, 2012) along with education courses and degrees based on an integrated knowledge to respond to the highly specific skills and competences required by the food manufacturing sector aimed at guaranteeing the quality and safety of foods for consumers. The distinctiveness of graduates in Food Science and Technology or Food Engineering, according to the country, is related to the multidisciplinary and highly specialised knowledge and science-based skills in food and in the processes needed to achieve food products with high quality and safety in agreement with legal requirements and consumers' expectations. Nowadays, Food Science and Technology/Engineering degrees are included in the educational offer of many universities in all EU countries even if many factors contributed to the development of courses with a large variety of learning outcomes and branches (science vs engineering), sectors of specialisation (technology, engineering, nutrition, safety, quality, food production chain) and degree titles. Graduates find jobs in various positions offered by the industry, public and private research centres, consultancy in the food sector as well as those related to food (e.g. packaging, raw materials production, food service). In this framework, FST professions play a key social role in keeping up standards and protecting the health of the consumers, giving food professionals the overriding responsibility of the assurance of the quality and safety of foods. These activities create a demand for highly qualified, experi- enced and certified specialists, who can, thanks to their skills, contribute to the achievement of the quality objectives of the complex and increasingly demanding food supply system. As a more general observation, the activity of food professionals and their impact on the health, safety and wellbeing of human society can be somehow compared with that of other professions like doctors, engineers and veterinarians, which for these reasons are officially recognised and regulated professions by law and/or by public authorities at national and/or EU level.

The attractiveness of either a profession or a group of professions is affected by a number of determinants. Those that affect the choice of a career can be either personal or situational (Super, 1980). Personal determinants may be awareness, attitudes, interests, needs-values, aptitudes and biological heritage. Situational determinants may be social structure, historical change, socioeconomic organization and conditions, employment practices, school, community and family. Of all these determinants, some of the situational ones can be modified by economic and employment politics, promoting the conditions to attract people to certain professions. According to Katz (1993), referred to by Reardon, Lenz, Sampson Jr, and Peterson (2000), at the time of choice of a profession, the main values are income, prestige, independence, security, variety, leadership, field of interest, leisure, early entry and helping others. The conclusions of the Archipelago of Thematic networks in the fields of Sciences and Technology forum in 2007 (TechnoTN, 2007) also stated some of these factors has being highly influential when choosing a profession. Clearly, high income and prestige are very important factors and these are usually characteristics that can be found in regulated professions as the lawyer or the medical doctor, professions that have existed for a long-time and are widely recognised by the society.

With the increasing innovation of the food industry and complexity of its services and products, consumer protection and public health policies may also justify the regulation of FST profession(s). The official recognition of a profession along with its regulation could also be a way of promoting its social and economic value that currently seems underestimated in the case of the 
jobs and positions in the food sector. Regulation of professions is justified when it improves consumer protection and public health (Garoupa, 2004). Moreover, the regulation of FST professions could also favour their attractiveness.

However, the purpose of regulation of a profession should be justified by its public interest and in the case of FST professions it is related to the assurance of consumer safety and/or correction of the asymmetry of information (for example, adverse selection of the worker in a specific role or position because of the employer's and/or consumers' lack of ability to judge and assess his/her skills and knowledge) when acquiring the services of the professionals (Garoupa, 2004).

With EU financial support, TRACK_FAST (https://www.trackfast.eu/) was a project involving 27 institutions from 16 European countries focused on the improvement of the skills and the attractiveness of FST professions through several ways, with particular emphasis on the study of regulation of professions.

In this paper the results of the analysis of the state of the art of the FST regulated professions requiring Higher Education qualifications in European countries is reported along with the differences between countries, as well as between the FST and other regulated food-related professions.

\section{Methods}

\section{$2.1 \quad$ Premises}

According to the Directive, 2005/36/EC of the European parliament and of the council of 7 September 2005 on the recognition of professional qualifications, a "regulated profession' means "a professional activity or group of professional activities, access to which, the pursuit of which, or one of the modes of pursuit of which is subject, directly or indirectly, by virtue of legislative, regulatory or administrative provisions to the possession of specific professional qualifications; in particular, the use of a professional title limited by legislative, regulatory or administrative provisions to holders of a given professional qualification shall constitute a mode of pursuit. Where the first sentence of this definition does not apply, a profession referred to in paragraph 2 shall be treated as a regulated profession" (art. $3)$.

In general, the regulation of a profession has the aim of assuring the quality of professional services in the public interest. The regulation of a profession involves the setting of standards of professional qualifications and practice, the keeping of a register of qualified persons and the award of titles, determining the conduct of registrants, the investigation of complaints and disciplinary sanctions for professional misconduct. The regulation can be applied to both the job market entry (the need for specific degree titles) and to the roles and activities that the enrolled professional can carry out. The regulation of a profession can be specified by national (or regional) state laws, by either compulsory or voluntary professional bodies as well as by the European Community (according to specific treaties, directives, decisions) (Paterson \& Ogus, 2003).

Taking into account the aims of the project in which this research has been carried out, the study was mainly focused on the analysis of the existing regulated food professions ruled by national laws and governmental authorities. On these premises we did not included those created by voluntary professional bodies (e.g. the Institute of Food Science and Technology in UK) even if they also focus their activities on the certification of the quality of their professional members.

\subsection{Data collection}

Information on FST regulated professions was gathered by contacting unions, professional associations, public servant categories/professions, as well as by visiting national and European websites hosting databases of regulated professions. The data collected for each regulated profession were: country, training/education required, date of implementation of regulation, professional training (if required), capability test (if required) and acts required by law to be signed by a regulated professional. Only professions that required a higher education diploma were included in this research (articles 11d and 11e of the Directive $36 / 2005$ ). This research did not include the profession of teacher, safety inspectors and 
engineer when regulated in general terms, i.e., just the use of the engineering title.

After the identification of FST professions, the mobility of FST professionals in Europe was analysed to understand if there was any influence of regulation on the mobility, a crucial aspect in the EU policy.

The study of the regulation of FST professions was completed by a comparative analysis with the non-sectorial related professions 'Nutritionist' and 'Dietitian' and a comparative analysis with the sectorial profession 'Veterinary Surgeon' that have some overlapping fields of activity with FST professions.

To develop the topic of regulation in the future, we have given an overview of regulatory instruments, of public interests for regulation and of institutions for implementation of the regulation that must present in the discussion of regulation on these premises.

\section{Results and discussion}

\subsection{Food Science and Technology regulated professions}

\section{Identification of professions}

According to the current EU legislation and the European Commission regulated professions database (http://ec.europa.eu/internal_market/ qualifications/regprof/), there are four professions that include in their title the term "food" (either in English or in the native national language) regulated in some EU countries, namely: Food Inspector, Food Chemist, Food Hygienist and Food Technologist. Based on the definition and competences of the regulated activities it appeared that the first two are professions strictly related to food inspection, which is out of the scope of this work, while the third one is more involved on medical activities not exclusively focused on those that characterise the FST professional.

Only the 'Food Technologist' profession was recognised to fit the scope of this study. The "Food Technologist" profession is regulated in four countries: Slovenia, Iceland, Greece and Italy. Oenologist, highly specialised profession in the area of wine production sector, was the other FST profession found in three EU countries (Italy, Portugal and Spain).

Apart from these professions, the Food Engineer profession was found to be regulated in Turkey (Table 1).

The analysis of the database (July 2013) highlighted the limited number of regulated professions in the FST sector and their heterogeneity. For some of them the regulation limits the competences of the professionals to specific activities and/or fields or professional sectors, with a meaningful different impact on their role in the society. This is the case of the approach of the regulation of the food-related professions in Slovenia. In this country only the "Food Technologist in the health sector" is regulated as the 'profession' according to the EC Directive $36 / 2005$, whilst it is not regulated when this profession is carried out in all the other professional sectors (e.g. industry or consultancy). In Slovenia, "Nutritionist and/or food organizer in school sector" is a regulated profession (at the levels defined by Article 11d and 11e) that also refers to activities applied only to a specific sector (i.e, schools), not to a wider field of service. This example indicates that the regulation of food professions in some countries has been developed only on the basis of either specific skills and professional competences or the sector where the professional applies them (e.g. health, education, industry) likely as a consequence of a specific demand. In this regard, it has to be noted that the regulation of these professions was driven by specific ministries (e.g. health and education) that need to assure and guarantee the health and wellbeing of the citizens by the employment of professionals with recognised and highly qualified competences.

On the other side, in Italy, Iceland and Greece, the national authorities have developed a different strategy and regulated the more general "Food technology" profession taking into account the wider scientific and technical skills and knowledge in the food sector.

In general, national law and government acts of the recognised food technology/engineering professions determine access to the profession, their activities and their market behaviour. On these bases a further distinction has to be made be- 
Table 1: Regulated professions of Food Science and Technology in European countries

\begin{tabular}{|c|c|c|c|}
\hline Profession & Countries & $\begin{array}{l}\text { National } \\
\text { act/law (year } \\
\text { of start) }\end{array}$ & $\begin{array}{l}\text { Acts that require the responsible to be } \\
\text { a recognized professional }\end{array}$ \\
\hline Food Engineer* & Turkey & 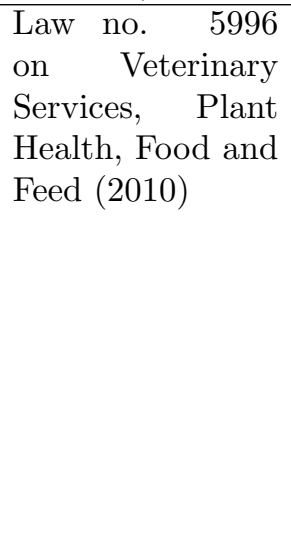 & $\begin{array}{l}\text { Food establishments that have equipment } \\
\text { power of at least } 30 \mathrm{hp} \text { and employing at least } \\
10 \text { personnel have to employ a food, chemical } \\
\text { or agricultural engineer of related sub-topic } \\
\text { or a veterinarian according to the work area. } \\
\text { If even more than one food engineer is em- } \\
\text { ployed in the establishment, Chambers of } \\
\text { Food Engineers (CFE) gives license to only } \\
\text { one of them but the others have to be mem- } \\
\text { bers of CFE. } \\
\text { On self-employment and consultancy services } \\
\text { the professionals, have to be registered by the } \\
\text { CFE to have a working license in the sector. }\end{array}$ \\
\hline Food Technologist & Italy & $\begin{array}{l}\text { National law } \\
59 / 94 \text { (issued by } \\
\text { the Ministry of } \\
\text { Justice) (1994). }\end{array}$ & $\begin{array}{l}\text { Quality control in industries and companies } \\
\text { of dietary foods must have a responsible } \\
\text { which is a Food Technologist or a graduate } \\
\text { from pharmaceutical technology, biology or } \\
\text { chemistry. }\end{array}$ \\
\hline Tecnologo Alimentare & & & $\begin{array}{l}\text { Pet food and animal feed companies must } \\
\text { have in a permanent position a professional } \\
\text { registered in one of these Orders: Food Tech- } \\
\text { nologist, Pharmacy, Biological Science, Vet- } \\
\text { erinary Medicine or Animal Production. }\end{array}$ \\
\hline Technológos trofímon & Greece & 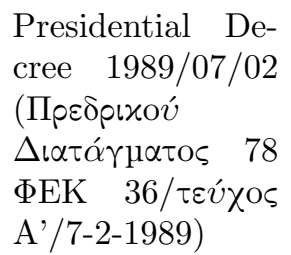 & None \\
\hline Matvælafrcingur & Iceland & $\begin{array}{l}\text { Regulation no. } \\
432 / 1987\end{array}$ & None \\
\hline $\begin{array}{l}\text { Živilski tehnolog } v \\
\text { zdravstveni dejavnosti }\end{array}$ & Slovenia & $\begin{array}{l}\text { ULRS, št.: } 33 / 04 \\
\text { in } 38 / 06\end{array}$ & None \\
\hline \multicolumn{4}{|l|}{ Oenologist } \\
\hline Enologo & Italy & $\begin{array}{l}\text { National law } 10 \\
\text { April } 1991 \text { n. } 129\end{array}$ & None \\
\hline Enólogo & Portugal & $\begin{array}{l}\text { Lei n. } \stackrel{\text { o }}{59 / 2009} \\
\text { de } 5 \text { de Agosto }\end{array}$ & None \\
\hline Enologo & Spain & Ley 50/1998 & None \\
\hline
\end{tabular}

*Information supplied the Chambers of Food Engineers of Turkey. 
tween the existing regulated professions in the food area. In Italy and Turkey, some highly qualified activities in specific food industries can only be performed by Food Technologists or Food Engineers professionals, respectively (Table 1). Only these two FST professions can be actually compared for the degree of regulation with the other widely recognized professions fitting the Directive, 2005/36/EC, while for Greece and Iceland only the access to the profession and their activities is ruled.

A possible cause of the limited number of regulated food technology/engineering professions in the EU could be the fact that in some EU countries the FST courses started as a branch of other well-known Higher Education courses whose degree was allowing access to already recognized professions (e.g. Chemistry, Engineering, Agronomy, Biological Sciences, etc.). This in fact has led to the regulation of access of the FST graduates and food professional to e.g. the agronomist, the chemist, the engineer profession and similar professions with an already recognized social status that have a correspondingly low interest in developing new, highly specific "food"-related professions.

\section{Mobility of FST professionals in Europe}

Directive, 2005/36/EC was issued to favour the exchange of professionals among the EC countries based on the definition of the minimum training requirements and on the tuning of the regulation. To understand the applicability of this scope to the FST professional, the number of professionals who achieved professional qualifications in one country (country of origin) and who applied for recognition in another country to practice there on a permanent basis was considered in the EC database of regulated professions. As expected also on the basis of the limited number of recognised food professions in the EU countries, the data available are scarce (and are also not complete for all countries) and only 14 cases were registered (2 for oenologist, 12 for Food Technologist), but it could be presumed that many cases of such cross-boarding have been not registered.

On the other hand, in respect to the well and long-time existing recognised professions like veterinarian, chemist and medical doctor, the food technologist one is rather new in the field of professions. For the professionals of the countries where the food technology profession is regulated this fact could also represent a limit for mobility in other EU countries.

Mobility of professionals in Europe and its potential impact on the job market, as well as on society, is not a justification for regulation, but it could be considered as a secondary effect and should be included in the debate of the regulation of professions as well as of the FST ones.

\section{The Order of Food Technologist professionals in Italy: a case study}

Since the end of 1980 in Italy, the association of graduated students of the Master degree in Food Science and Technology undertook actions aimed at achieving official recognition by law of the highly specific professional competences and expertise of the Food Technology professionals and in particular, those related to quality and safety of food products, food processing, management of food production and distribution, not covered by any of the already existing professionals in Italy.

The interest to regulate the Food Technology professional in Italy was, thus, of both public interest (quality and safety of foods) and private as it could enhance the availability of job positions and consultancy activities for highly specialised Food Technologist professionals registered in the official board of the Order. The support for the regulation of the food technologist by public health bodies and food private organisations was minor because they were not able both to foresee the importance of the multidisciplinary competences of this professional category and in invest in highly qualified employees.

The profession was eventually recognised by the Italian Ministry for Justice (Law n. 59, 1994) and the regulation act (Decree of the President of the Republic, 19 July 1999, $n$. 283) defined specifically the activities covered by the food technologist (FT) professional and the main structure of the Order comprising one national and 11 regional Board sections at which each FT professional has to be registered (www. 
tecnologialimentari.it).

The Law and the Act regulate the degree for the access to the profession (Master degree $/ 2^{\text {nd }}$ level degree in Food Science and Technology), the compulsory examination to assess the skills and capabilities of the applicants, the specific competences and activities of the professionals and the annual fee for the registration; it also imposes a code of conduct. On these bases, the law regulated mainly the FT professional as consultant but later on, two food industry categories (cattle and animal feed and foods for specific consumer categories, e.g. baby-foods, fortified food, food supplements) added the food technologist registered in the Order among those categories of workers that could be involved in the quality control and assessment of the processing as required by specific Italian laws.

The Food Technology professional in Italy is nowadays regarded as a multidisciplinary, technical (not health) professional with impact on public health and whose activities respect a code of conduct that imposes an ethical approach in the work activity. This profession, however, is not recognised for job positions in the public health sector.

Since 2002 when the national board started its activities, the involvement of its representatives as consultants in public entities and projects has progressively increased. In some universities the representatives of the regional boards are also included in the commission of accreditation/assessment/implementation of the FST programmes.

The FT Boards have been active since 2001 and about 2000 food technology professionals are registered in Italy (data from July 2013). The regulation applies on a compulsory basis, for the FT working both as individual professional (consultant) as well as to those employed in some food safety organisations and authorities for which the registration to an Order is a pre-requisite. Besides the aforementioned, two food industry categories that require that the FT employed in their Quality Control/Assurance labs are registered by the Order of FT, for the remaining graduates in Food Science and Technology employed in the food sector, the registration by the Order is made on voluntary basis. However, the latter represents an added value when applying for a job position especially in public and private institutions dealing with health and food related safety issues.

Currently, the regulation of the Food Technologist profession, as well as all the regulation of other professions in Italy, is undergoing a reform that aims to further improve the quality and value of the professionals.

\subsection{Comparative analysis with other professions}

\section{Comparative analysis with the non- sector related professions Nutritionist and Dietitian}

The identification and analysis of the currently regulated professions in the field of nutrition were also included because in some countries (e.g. Slovenia) the study programmes in the field of "Food Science Technology", "Food Safety" and "Nutrition" are linked (at BSc and even at MSc level). Until few years ago this was also true for dietetics/clinical nutrition, with people currently employed on these fields mainly studying in the field of FST. If one of the goals of all these courses is also the improvement of the study curricula so that they better fit the career paths and thus also the regulated professions; this has to be taken into account. Besides this, regulation in the field of nutrition/clinical nutrition/dietetics seems to be useful as an example of consolidated practice of regulation.

According to European Commission regulated professions database, the profession of Nutritionist, Clinical nutritionist or of Food organizer (Directive $36 / 2005$ ) is regulated in six countries (Slovakia, Slovenia, Czech Republic, Iceland, Norway, Malta). The profession of Dietitian (according to the Directive 36/2005) is regulated in 12 countries (Ireland, Italy, Iceland, Hungary, Germany, France, Finland, Denmark, Cyprus, Belgium, Austria and UK).

The EU statistical data (not complete for all countries) of the number of professionals who obtain professional qualifications in one country (country of origin) and apply for recognition in another country to practice there on a permanent basis currently (July 2013) correspond to 100 for 
the profession of "Nutritionist" and 1047 for the profession of "Dietitian".

\section{Comparative analysis with the sectoral profession Veterinary Surgeon}

This profession, which is very ancient in the history of the recognized professions, is partially related to the field of FST, and belongs to the sectoral professions and benefits from automatic recognition by the Directive $36 / 2005$ on the basis of harmonization of minimum training requirements that includes also other professions like medical doctors, nurses, dentists, architects, pharmacists and midwives.

According to the EC database, it is currently under regulation in 32 European countries. It can be considered as an example of good practice, because of the professional relatedness and also high number of statistically registered crossborder decisions taken on professionals who obtain professional qualifications in one country (country of origin) and apply for recognition in another country to practice there on a permanent basis. From recent data (July 2013) of crossborder decisions, 6609 in total for all EU countries were registered.

It is necessary to observe that the veterinary surgeon is considered a health-related profession and some of the activities that are done by them are overlapping with those recognized by the food technology professional (quality control and assurance of the food production chain of meat and milk derivatives, in particular).

\section{Regulatory instruments}

Professions may be regulated for different reasons and consequently in different ways and with different restrictions. As referred to before, professions are regulated if there is a public interest in assuring consumer safety and/or correcting asymmetry of information when acquiring the services of the professionals (Garoupa, 2004). Consumer health/safety is the main reason for the regulation of the medical doctor and for the Italian food technologist whilst, for example, the information asymmetry is the main reason for the regulation of lawyers, where it is necessary to ensure that the consumer is acquiring competent services when $\mathrm{s} / \mathrm{he}$ is not able to evaluate by her/himself the quality of the services s/he's acquiring. For example, adverse selection (because of the consumers' lack of ability to judge the quality of professionals) should be protected by regulation (Garoupa, 2004). Various instruments are used to regulate a recognized profession and implying a series of restrictions that could be classified in five major groups (Garoupa, 2004):

i. Entry restrictions with consequent professional monopoly rights (required skills acquired by education and training)

ii. Restrictions on advertising and other means of promoting competition with the profession

iii. Restrictions on fees and fee contracts

iv. Restrictions on organizational forms

v. Restrictions on conduct and procedures.

Entry restrictions usually refer to the academic qualifications. In Italy, the access title for the food technologist profession is the second cycle (or Master) degree in Food Science and Technology; an additional exam carried out according to an official rule is compulsory to assess the high quality of the future professionals. In Greece, the Association of Food Technologists requires only the first cycle on Food Technology as prerequisite for the food technologist profession.

Restrictions on advertising, fees and organizational forms apply also to the Italian food technologist professionals while they do not apply in the others here mentioned since their market for the commercialization of services is not the general public but private companies or governmental departments.

Restrictions on conduct are part of the regulation particularly in self-regulation, as is the situation of the Italian Food Technologist and of the seven wide recognized professions. 


\subsection{Discussion}

\section{Public interests for regulation}

The main market failure that applies to professional markets is information asymmetry (Stephen \& Love, 1999). Under such conditions the market usually fails to produce optimal quantity and quality of the professional service. As a consequence, the economic efficiency is also limited. Besides this aspect, protection for the consumer of these professional services is necessary to guarantee quality. In summary, quality, confidence, honesty and trust should be achieved and thus optimal protection and safety for consumers of professional services and professionals as well.

By translating the concepts of public interest in the field of FST (including food safety), it appears evident that the regulation of FST professions could be perceived as a need to better guarantee the quality and the safety of food production along the whole food chain from the farmer, food processor, caterer, retailer etc., to the final consumers, e.g. protection and/or contribution to health -, and thus also to keep public health at a high standard and public costs for health services as low as possible.

Food safety is a main issue in the entire food supply chain with main concern being processed foods. In 2011 hundreds of thousands of food-borne disease outbreaks occurred in Europe (EFSA, 2013) and some of them with cross-border trade consequences and economic impact. The media, press releases and electronic sources, including social media and email, more and more facilitate the dissemination of the risk associated to foods and food production. The outbreak of Shiga-toxin producing Escherichia coli in Germany that occurred in 2011, was the last large outbreak in Europe but more recent ones can be mentioned involving both other pathogenic microorganisms (Campylobacter, Salmonella, Cl. Botulinum, etc.) and chemical contaminants. Information asymmetry is also an issue in FST services. Although on a smaller scale when compared with the seven widely recognized professions, nowadays FST services are acquired by particular "consumers" - e.g., some SMEs, restaurants - for which the lack of ability to judge the quality of the FST professional is a reality. A large company, with qualified professionals, may also be interested in hiring a FST professional registered in a professional association that guarantees his/her skills and expertise in the specific sector and his/her job activity according to an ethical code, possibly at a correspondingly higher salary.

Until now, the existing regulated professions other than the Food Technology ones, such as Agronomist, Chemists, etc., may apply their professional skills and competences only in specific branches of the food chain (raw material production, food analysis, etc.) as the education and training as well as the career path of these latter ones is in general "sectoral", lacking the multi- and trans-disciplinary expertise of a potential Food technologist professional.

\section{Institutions and organisations supporting the implementation of the regulation}

The current state in EU highlights the main differences in the recognition of the regulated professions in the various countries. In some of them the recognition procedures were mainly driven by the government and/or specific ministry and sectoral authorities (which are not FST, but more general e.g. health, education). This is the reason for professional discrepancies, like the fact that "Food Technologist in the health sector" and "Food organizer in the school/education sector" are regulated professions in some countries, but "Food Technologist in non-health sector" or "Food organizer in the school/education sector" are not regulated professions. This shows that the authorities are mostly able to recognize only some specific expertise among the overall skills of the FST professional. This could be due to limited knowledge of the overall skills of the FST professional or to too high importance given to some specific skills.

The role of professional associations in the recognition and regulation of FST professions can be crucial to the development of the FST professions. In at least three countries where the regulation of the FT profession was analyzed (Italy, 
Iceland, Greece), the professional associations and/or the specific ministry (e.g. for industry) and authorities are involved in active definition of collective agreement about the (minimum) salary.

In Italy, the association of the master degree graduates in FST (Associazione dei Laureati nelle Discipline Alimentari, currently ALDAL, www.aldal.it), which was founded in the early 1970s was very active in respect to the recognition of the Food technology profession and they promoted its regulated profession.

However, this approach could be different depending on the country and its economic, political and social state. Generally, the role of professional associations in the recognition and regulation of FST professions in EU seems to be poor (or even not present at all in some countries) and in general their activities are mainly aimed at favouring the relationship between their members as well as the maintenance of a high quality standard competence and skills by organizing training activities.

\section{Conclusions}

The current state of the regulated professions in the food sector in Europe reports a few examples of the Food Engineer, Food Technologist and Oenologist in a rather limited number of countries. The Food Technologist in Italy and the Food Engineer in Turkey were found to be the only completely regulated FST professions in Europe.

Food production and professional regulation have evolved over the years and raised the debate on the regulation of FST professions. Moreover at European as well as at national level there is a main political debate on the reform of the overall regulation of the professional qualifications along with the Directive 2005/36 with general proposals that are envisaging an overall deregulation to limit the restrictions on mobility.

Despite of this "in progress" state of the regulation of the qualified professions, it is important to encourage further discussion on the potential and role of food-related professions with the involvement not only of the academia but also of other policymakers and authorities at national and European level. This will contribute to keeping high the standards for quality of education and training of these professionals and improve the quality and safety throughout the food chain and favour its modernisation.

\section{Acknowledgements}

This work was funded by the Commission of the European Communities Framework 7 Programme through the project 'TRACK_FAST: Training Requirements and Careers for Knowledge-based Food Science and Technology in Europe' an SP1-Cooperation, Coordination and Support Action, grant agreement number: KBBE 227220. The funders had no role in the details of the study design, data collection analysis and interpretation, writing of the report nor decision to publish.

\section{References}

Directive. (2005/36/EC). of the European Parliament and of the Council of 7 september 2005 on the recognition of professional qualifications.

EFSA. (2013). The european union summary report on trends and sources of zoonoses, zoonotic agents and food-borne outbreaks in 2011. Scientific Report of EFSA and ECDC. EFSA Journal, 11(4), 3129.

FDE. (2012). Data \& trends of the european food and drink industry 2012. Food Drink Europe. Retrieved from http : / / www . fooddrinkeurope.eu/uploads/publications_ documents/Data_-Trends_(interactive).pdf

Garoupa, N. (2004). Regulation of professions in the us and europe: a comparative analysis (American Law \& Economics Association Annual Meetings No. 1053). American Law \& Economics Association. Retrieved from http://EconPapers.repec.org/RePEc:bep: alecam:1053

Katz, M. (1993). Computer assisted career decision making: the guide in the machine. Hillsdale, NJ: Lawrence Erlbaum.

Kostaropoulos, A. E. (2012). Food engineering within food sciences. International Journal of Food Studies, 2, 109-113. Retrieved from 
Regulation of FST professions in Europe $\mid 135$

https: / / www.iseki-food.net/simplenews / 3549

Paterson, M., I. nad Fink \& Ogus, A. (2003). Economic impact of regulation in the field of liberal professions in different member states. Regulation of Professional Services. Final Report - Part 1. Study for the European Commission, DG Competition. $\mathrm{Vi}$ enna: Institute for Advanced Studies. Retrieved from http : / / ec . europa.eu / competition/sectors/professional_services / studies/executive_en.pdf

Reardon, R. C., Lenz, J. G., Sampson Jr, J. P., \& Peterson, G. W. (2000). Career development and planning: a comprehensive approach. Pacific Grove, CA: Brooks/Cole.

Stephen, F. \& Love, J. (1999). Regulation of the legal profession. in: encyclopaedia of law and economics. Ghent: University of Ghent, 987-1017.

Super, D. E. (1980). A life-span, life-space approach to career-development. Journal of Vocational Behavior, 16(3), 282-298. doi:10.1016/0001-8791(80)90056-1

TechnoTN. (2007). Conclusions of the TechnoTN Forum. Retrieved from http://www. sefi. be/technotn/?page_id $=78$ 